years between those who have seen the campaign vs those who have not. Reduction in injury deaths among the target population was associated with the campaign period.

Conclusions A well-developed injury prevention social marketing campaign based upon input from the target audience can result in significant changes in awareness, attitudes and behaviours, which was associated with decreased injury mortality.

\section{DEVELOPMENT AND PILOT TEST OF AN MHEALTH TRAUMA REGISTRY IN OMAN}

${ }^{1 \S}$ Amber Mehmood, ${ }^{1}$ Edward Chan, ${ }^{1}$ Katharine Allen, ${ }^{2}$ Ammar Al Kashmiri, ${ }^{2}$ Ali Al Busaidi, ${ }^{1}$ Kent Stevens, ${ }^{3}$ Abdullah Al Maniri, ${ }^{1}$ Adnan A Hyder. ${ }^{1}$ Bloomberg School of Public Health, Johns Hopkins University, Baltimore, USA; ${ }^{2}$ Ministry of Health, Sultanate of Oman; ${ }^{3}$ The Research Council of Oman

\subsection{6/injuryprev-2016-042156.338}

Background Trauma registries (TRs) play a vital role in the assessment of trauma care, but are often underutilised in countries with a high burden of injuries. We postulated that emerging technologies in trauma and injury surveillance could enable the design of a tablet-based application for health care professionals. This would be used to inform trauma care and acquire surveillance data for injury control and prevention in the Sultanate of Oman. Methods The study comprised of three steps. a) Consensus on variables to record the quality of trauma care and injury surveillance. b) Design of an electronic tablet-based application and pretesting at the Johns Hopkins International Injury Research Unit c) Pilot study of electronic registry at two large hospitals in the Sultanate of Oman.

Results The application was designed to provide comprehensive information on each trauma case from the location of injury until discharge, so the variables were organised to cover eleven domains of information, with standardised format of data collection. Internet connexion was required only at the time of data transfer to the electronic database. Pilot study included training and induction of nurse data collectors, data collection over six months, data quality control, and data analysis. A nurse-based pilot study demonstrated that the application was user friendly, reliable, and feasible in the current setting. With approximately 2600 completed cases, the data was found to be accurate and reliable in $>93 \%$ of cases.

Conclusion Initial results show the promising potential of a userfriendly, comprehensive electronic TR to develop a multicenter trauma database. The pilot test in two hospitals indicates that the registry can be used in multiple hospitals. Stakeholders engagement, training of the staff and supervised induction is the key to success and help improve injury surveillance as well as quality of trauma care.

\section{Violence}

\section{Parallel Tue 3.4}

\section{WRAPAROUND CARE FOR YOUTH INJURED BY VIOLENCE: A PILOT RANDOMISED CONTROL TRIAL}

\footnotetext{
${ }^{1,2}$ Carolyn Snider, ${ }^{1}$ Wanda Chernomas, ${ }^{1}$ Karen Cook, ${ }^{1}$ Depeng Jiang, ${ }^{1}$ Terry Klassen ${ }^{1}$ Sarvesh Logsetty, ${ }^{2}$ Jamil Mahmood, ${ }^{1}$ Elaine Mordoch, ${ }^{1}$ Trevor Strome, ${ }^{2}$ Floyd Wiebe. ${ }^{1}$ University of Manitoba, Canada; ${ }^{2}$ Winnipeg's Gang Action Interagency Network, Canada
}

Background Youth injured by violence is a major public health concern in Canada. It is the fourth leading cause of death in youth and the foremost reason youth visit an emergency department (ED). In Winnipeg, 20\% of youth who visit an ED with an injury due to violence will have an ED visit for a subsequent violent injury within one year. Youth injured by violence are in a reflective and receptive state of mind, rendering the ED setting appropriate for intervention.

Methods We completed a pilot randomised control trial in November 2015 comparing wraparound care for youth age 14 24 who were injured by violence to standard ED care. Youth were excluded if their injury was due to child maltreatment, sexual assault or self-harm. An adapted pre-consent randomization methodology was used. The intervention was developed using a community based participatory research approach. Wraparound care was delivered by a support worker with lived experience with violence. Support workers were on call 24/7 in order to start the intervention in the ED and take advantage of the "teachable moment." Care continued in the community for approximately one year.

Results A total of 133 youth were randomised (68 intervention, 65 control) in one year. There was no difference in age, gender, or severity of injury between the two groups. Patients randomised to the intervention spent a median of 30 minutes less in the ED than those receiving standard care $(p=0.22)$. Youth are safely housed, have enrolled in education opportunities, and are engaged in addictions care. Results of a chart review examining repeat visits to the ED for violent injury, substance use and mental health will be completed in late 2015 and will be presented.

Conclusions There were no differences between standard care and intervention groups on baseline characteristics reflecting effective randomization. The introduction of an intervention at bedside in the ED did not have a negative impact on patient length of stay.

\section{SUSTAINABLE DEVELOPMENT GOAL 16.1: ARE NONKILLING SOCIETIES POSSIBLE?}

Joám Evans Pim. Åbo Akademi University, Finland, and Centre for Global Nonkilling, Hawaii

\subsection{6/injuryprev-2016-042156.340}

Background In September 2015 the United Nations adopted the newly drafted Sustainable Development Goals (SDGs), as the post-2015 development agenda. The SDGs replaced the Millennium Development Goals that expired at the end of 2015 and, for the first time, include an item explicitly addressing the need for "peaceful and inclusive societies", setting the goal to "significantly reduce all forms of violence and related death rates everywhere" (16.1).

Description of the Problem The SDGs will significantly shape international development policies until 2030 and set targets to be met by major national and international agencies. Besides the overarching SDG 16.1, other goals specifically address different types and contexts of violence $(4 \mathrm{a}, 4.7,5.2,5.3,16.2)$ and a number of risk factors closely connected to violence. However, the possibility of significantly reducing death rates and building killing-free societies is still strongly questioned.

Results The field of violence prevention has grown significantly over the past decade, signalled in 2002 with the publication of the World Report on Violence and Health that clearly identified violence as "a preventable disease". This paper explores some of the accumulative supportive evidence for violence prevention 